\title{
Novelty as a determinant of spontaneous alternation in children'
}

\author{
N. C. Ellis and M. D. Arnoult \\ TEXAS CHRISTIAN UNIVERSITY
}

\begin{abstract}
Abstraet
Nursery school children traced a series of T-mazes under varying and nonvarying stimulus conditions in a situation arranged such that all external stimulus cues could be apprehended by Ss throughout the entire task. The results of the experiment were interpreted on the basis of Berlyne's (1960) novelty hypothesis, and it was concluded that spontaneous alternation appeared to be related to the activating properties of novel stimuli.

\section{Problem}

Spontaneous alternation has been the focal point for a considerable amount of hypothesis formulation and theory testing in psychology. Hull (1943) attributed spontaneous alternation to the action of responseproduced inhibition $\left(\mathrm{I}_{\mathrm{R}}\right)$, whereas Glanzer (1953) attributed it to stimulus satiation $\left(\mathrm{I}_{\mathrm{S}}\right)$. Thompson (1960) combined both of these explanatory mechanisms into a two-factor theory. Montgomery (1952) regarded alternation as a special case of exploratory behavior, based on a curiosity drive, and Berlyne (1960) suggested that curiosity is behavior initiated by the activating properties of novel stimuli. There is considerable predictive overlap among these various formulations, and it is difficult to generate differential predictions from them, although Thompson had some success in testing separately the effects of $\mathrm{I}_{\mathrm{R}}$ and $\mathrm{I}_{\mathrm{S}}$.

One difficulty in testing any of these hypotheses in the standard $\mathrm{T}$-maze is that the stimuli related to the alternatives are not available to $S$ until the choice point and thereafter. Thus, similarity between stimulus cues or response-produced cues on any two successive trials is greatest in the stem of the "T," and when $\mathrm{S}$ selects the opposite arm on the second of any pair of trials, the trial-to-trial similarity is minimal in that arm. Between these extreme points (stem and arms) there is a gradient of decreasing similarity which steepens in the area of the choice point.

If a situation could be arranged in which all of the external stimulus cues are apprehended by $\mathrm{S}$ throughout the entire task and are systematically varied from one task to the next, it might be possible to determine the differential effects of stimulus satiation and of novelty. Such a task was produced by having children trace a series of $\mathrm{T}$-mazes under varying and nonvarying stimulus conditions. On the basis of Berlyne's hypothesis concerning the effects of novelty, three hypotheses were formulated with respect to the behavior expected on the task: (1) If stimulus conditions remain constant on successive trials, alternation will exceed chance occurrence; (2) If stimulus conditions are varied from trial to trial, alternation will not exceed chance occurrence; and (3) Regardless of the outcome of the previous hypotheses, alternation under conditions of stimulus variation will be less than alternation under constant stimulus conditions.

Subjects

The Ss were 16 girls and 12 boys selected from a day nursery school in Grand Prairie, Texas. The 28 children were between the ages of four and five, and they comprised the total population of the school.

\section{Apparatus}

T-diagrams, $41 / 2$ in in height and width, were drawn on $41 / 2$ by 6 in cards of Alladin construction paper. The thickness of both the perpendicular stem and horizontal arm was 1 in. Crayola crayons were used as marking instruments.

\section{Procedure}

The Ss were assigned randomly to two groups, with the restriction that each group have 6 boys and 8 girls. All Ss were right-handed.

The experiment consisted of 20 trials for each S. Group 1, using blue crayons, traced blue T-outlines reproduced on white backgrounds, and the crayon color, T-outline, and background remained constant throughout the trials. Group 2 performed the task under simulated conditions of novelty in which no particular colored $\mathrm{T}$-outline, crayon or background appeared more than one time in the series of trials.

Each $\mathrm{S}$ was tested individually in one of the nursery school rooms. The task cards were placed on a table in a long row and each card and marking crayon covered with a white sheet of $81 / 2$ by 11 in construction paper. The Ss were brought into the test room individually and given simple instructions regarding the task. Each $\mathrm{S}$ was given one practice trial to ascertain the understanding of the directions. The $\mathrm{S}$ was given as much time as needed to draw, but on completion of a trial he was immediately presented the next task diagram.

\section{Results}

Table 1 shows the percent of Ss in each group alternating on each trial. It can be seen that Group 1 (Constant) alternated consistently more than Group 2 (Novel). The number of alternations in each group was tested by $\mathrm{X}^{2}$ analysis to determine the probability of chance occurrence. The analysis revealed that the Constant Group showed significantly more than chance alternations $\left(\mathrm{X}^{2}=4.7 ; 1 \mathrm{df} ; \mathrm{p}<.05\right)$ and the Novel Group performed significantly fewer than chance alternations 
Table 1

Percent of Ss Alternating on Each Trial Under

Novel and Constant Stimulus Conditions

\begin{tabular}{ccc|ccc} 
Trial Constant & Novel & Trial Constant & Novel \\
\hline 1 &..- &.- & 11 & .64 & .43 \\
2 & .71 & .50 & 12 & .64 & .43 \\
3 & .64 & .57 & 13 & .64 & .50 \\
4 & .64 & .43 & 14 & .64 & .36 \\
5 & .50 & .36 & 15 & .71 & .28 \\
6 & .57 & .43 & 16 & .50 & .36 \\
7 & .64 & .50 & 17 & .57 & .28 \\
8 & .64 & .36 & 18 & .50 & .43 \\
9 & .57 & .28 & 19 & .36 & .14 \\
10 & .71 & .50 & 20 & .43 & .36
\end{tabular}

$\left(X^{2}=5.9 ; 1 \mathrm{df} ; \mathrm{p}<.05\right) .{ }^{2}$ The distributions of alternations in the two groups were examined for homogeneity of variance, and the difference between the means subjected to a "one-tailed"' $t$ test. The analysis $(t=2.28 ; 26 \mathrm{df}$; $\mathrm{p}<.01)$ showed the difference in mean alternations between the two groups to be statistically significant. These results were interpreted as supporting all three hypotheses of the experiment.

\section{Discussion}

It appears that Hull's hypothesis of $I_{R}$ cannot account for the difference in alternation behavior exhibited by the Constant and Novel Groups. Both groups had equal opportunity to develop $I_{R}$, therefore, the number of alternations should have been equal. The issue is not quite as clear in the case of $I_{S}$. In Glanzer's formulation, the choice of a "T"-arm depends upon the relative satiation produced in the past by the two alternatives. In the present experiment $\mathrm{S}$ is exposed to both arms of the " $T$ " on every trial, and so should be equally satiated for both. It might be argued that the act of turning causes $S$ to attend more closely to the arm entered, and thus one could use $I_{S}$ as an explanation of the results of the Constant Group. However, such an explanation is at best vague when the results of the Novel Group are considered from a similar standpoint. To the extent that the successive mazes were similar to each other, this argument would predict increased alternation. The fact that some of the stimulus properties were changed on every trial would argue for a reduction in alternation. In either case, there appears to be no basis for predicting anything less than a chance frequency of alternation.
An explanation of the present results cannot easily be derived from Montgomery's concept of a curiosity drive either. There is no reason to suspect that the Ss in one group were more curious than those in the other group, except as a result of the variation in stimulus conditions. On the other hand, Berlyne's hypothesis that spontaneous alternation is related to the activating properties of novel stimuli appears to be relevant. Of course, Berlyne's original formulation was derived from standard $\mathrm{T}$-maze tasks in which $\mathrm{S}$ is exposed only to the stimuli associated with the particular arm of the maze which is chosen. However, Berlyne's awareness that his hypothesis might be extended to the kind of task situation employed in the present experiment is indicated by his statement that:

..... whether the presence of the consequent stimuli at the time of selecting the response makes a difference or not is a question that calls for some research ..... (p. 130).

The finding that providing new stimulus values for cues on every trial (Novel Group) leads to a reduction in spontaneous alternation to a point below chance level is consistent with Berlyne's model of the drive process. Encountering novel stimuli on every trial maintains the necessity for detecting, categorizing, and interrelating these novel stimuli provides the required cortical activity to produce cortical inhibition of the RAS (i.e., "reinforcement," in Berlyne's model). The additional cortical stimulation provided by the feedback from varying response characteristics, particularly the cortical activity involved in making a different "decision," would be unnecessary and even detrimental to the efficient functioning of S. However, when the stimulus conditions remain constant, as occurred for the Constant Group, there is danger that cortical activity might drop to a level below that appropriate for cortical control of the RAS. The additional stimulation, both external and internal, derived from alternation would help maintain the desirable level of activity in the cortex.

\section{References}

BERLYNE, D. E. Conflict, arousal, and curiosity. New York: McGraw-Hill, 1960.

GLANZER, M. Stimulus satiation: An explanation of spontaneous alternation and related phenomena. Psychol. Rev., 1953, 60, 257-268.

HULL, C. L. Principles of behavior. New York: Appleton-CenturyCrofts, 1943.

MONTGOMERY, K. C. Exploratory behavior and its relation to spontaneous alternation in a series of maze exposures. J. comp. physiol. Psychol., 1952, 45, 287-293.

THOMPSON, M. E. Alternation in a T-maze as a function of three variables. Psychol. Rep., 1960, 7, 103-110.

Notes

1. The uuthors wish to thank Ethel Parker and Alice Waggoner, Nursery School Superintendents, Grand Prairie, Texas, for their helpful cooperation in providing facilities and Ss for this study. 2 . This result was unexpected in that the second hypothesis predicted only that alternations would not exceed chance frequency for this group. 